JPPIPA, Vol.6 No.1 2021
Jurnal Penelitian Pendidikan IPA
htt//journal.unesa.ac.id/index.php/jppipa

\title{
ANALYSIS OF STUDENTS' ABILITY TO IDENTIFY SYMBOLIC REPRESENTATIONS IN CHEMISTRY
}

\section{Martini}

Departmen of Science Education, Faculty of Mathematics and Natural Sciences, Universitas Negeri Surabaya, Indonesia

\begin{abstract}
To describe the behavior of matter and energy, chemists classify them in three distinct domains: macroscopic, microscopic, and symbolic. The ability to use these three representations is the basis for understanding concepts in chemistry. This study aims to analyze students' ability to identify symbolic representations in chemistry. The research design uses a one shot case study. The subjects of this study were students of prospective science teachers as many as 85 students. Data collection techniques using tests and rubrics. The results showed that of the ten symbolic representation statements, only three statements achieved the highest percentage of correct answers, namely statements about writing ionization reactions and writing electron symbols. There are two statements where almost 90 percent of students answered incorrectly. The statement is about reversible or irreversible reaction equations and exothermic reaction equations. From this research, it can be concluded that students' ability to identify symbolic representations in chemistry still needs to be improved, because the average score is still low.
\end{abstract}

Keywords: Ability to identify, Symbolic representation, Chemistry 


\section{INTRODUCTION}

Chemists study and describe the behavior of matter and energy in three different domains: macroscopic, microscopic, and symbolic. These domains provide different ways of considering and describing chemical behavior. Macro is a Greek word meaning "big” (William R. Robinson, 2015). The macroscopic domain is familiar to us. It is the realm of an everyday is directly observed by the human eye or touch. The macroscopic domain includes chemistry in everyday life or in the laboratory, where we can observe and measure physical and chemical properties, or observe changes such as density, solubility, and flammability.

The domain of microscopic chemistry exists in the imagination. Micro also comes from a Greek word meaning "small." Most subjects are in the domain of microscopic chemistry, such as atoms and molecules. Subjects are so small that they are difficult to see even with a standard microscope, so they often have to be drawn in mind. Other components of the microscopic domain include ions, electrons, protons, neutrons, and chemical bonds, each of which is too abstract to look at. These domains include the metal atoms in the wire, the ions that make up the salt crystal, where changes in the molecules can result in a color change, the conversion of nutrient molecules into energy in cells, and the heat change from the bonds that join the atoms together (William R. Robinson, 2015).

The symbolic domain contains a specialized language used to represent components of the macroscopic and microscopic. Chemical symbols (such as those used in the periodic table), chemical formulas, and chemical equations are part of the symbolic domain, as are graphs and figures. We can also consider calculations as part of the symbolic domain. These symbols play an important role in chemistry because they help describe the chemical behavior. One of the challenges for students learning chemistry is recognizing that the same symbols can represent different things in the macroscopic and microscopic domains, and one of the features that makes chemistry fascinating is the use of a domain that must be imagined to explain behavior in a domain that can be observed

One example of the symbolic use in chemistry, is the kinetic equation which serves as a bridge between the microscopic domains and the behavior of macroscopic irreversible processes through the description of hydrodynamics in terms of intermolecular collisions(Demirel and Gerbaud, 2019).

To understand concepts in chemistry, students must be able to perform higher levels of mind processing using an internal representation or a mental model which has been constructed using all three macroscopic, microscopic and symbolic representations (Sujak \& Daniel, 2017; Sunyono, Yuanita, \& Ibrahim, 2015; Chandrasegaran et al., 2007; Johnstone, 1991).

From the explanation above, the author feels the need to analyze the students' ability to understand symbolic representations because this is one of the basics for understanding chemical concepts.The research question that can be formulated here is how is the student's ability to identify symbolic representations?

\section{METHOD}

The research design uses a one shot case study. The subjects of this study were prospective science teacher students as many as 85 students. Data collection techniques using tests and rubrics. The test instrument consists of two parts, namely: (1) ten symbolic representation statements, which must be determined true/false, accompanied by reasons, (2) graphic images of exothermic reactions, which must identify the six symbolic representations contained in the image.

In ten statements of symbolic representation, each correct answer is given a score of one, while for correct answers and correct reasons, a score of 2. For the identification of graphic images of exothermic reactions, each identified symbolic representation is given a score of 2 (Garza \& Grajales, 2011). Data were analyzed descriptively quantitatively with graphical representations containing: (1) the percentage of correct answers, (2) the percentage of correct answers and incorrect reasons. The representation is in the form of a table containing the average value.

\section{RESULTS AND DISCUSSIONS}

From the results of the study, it was found that the students' ability to identify ten symbolic representation statements is shown in Figure 1 below.

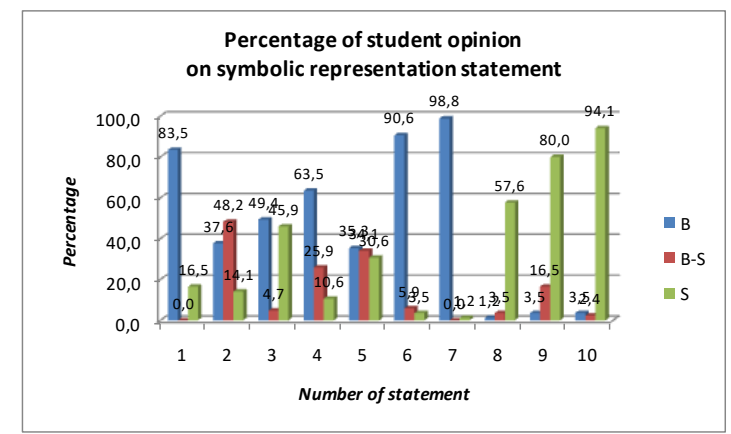

Figure 1. Percentage of student opinion

Note:

$B$ is the correct answer; $B-S$ is the correct answer, but the reason is incorrect; and $S$ is the incorrect answer. 
Figure 1 shows that in statements 1,6 , and 7 , the percentage of students who answered correctly was very large, while in numbers 9 and 10 it was the opposite, the percentage of students who answered incorrectly was very large.If you look closely, the symbolic representation statements for numbers 1,6 , and 7 are already very well known to students. The statement is about writing ionization reactions and writing electron symbols.At number 9, the symbolic representation for the reaction equation is reversible or irreversible. Students still don't really understand whether the reaction must use an alternating arrow or a one-way arrow. In number 10 of the exothermic reaction equation, students also do not understand that the heat of reaction $(\Delta \mathrm{H})$, must be negativeto show that there is heat released in the reaction.

Numbers 4 and 5 are symbolic representations for the filling of electrons in the orbitals. The percentage of students' correct answers on number 4 is higher than number 5, even though it represents the same thing.

The symbolic representation for number 4 and 5 , as follows.
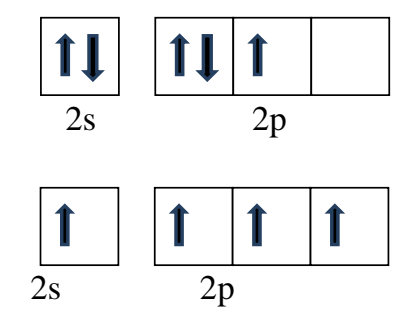

In question number 4 , there are $63.5 \%$ of students who remember and understand Hund's rule, that orbitals with the same energy are filled first by one electron in the same direction, then the remaining electrons are filled as electron pairs with opposite direction of arrow (Ebbing \& Gammon, 2009).

In question number 5 , only $35.3 \%$ of students answered correctly with the right reasons, so only $35.3 \%$ of students remembered or understood the Aufbau rule, that the filling of electrons in an orbital starts from the lowest energy level to a higher energy level. high, so the s orbital must first be filled with 2 electrons, then the rest occupy the $2 p$ orbitals (Ebbing \& Gammon, 2009).

From graphic images of exothermic reactions, students are expected to be able to identify six symbolic representations contained in the images, including: (1) graphic modeling of exothermic reactions; (2) exothermic reaction equation; (3) the state of the substance (in reactants and products); (4) decomposition reactions; (5) formation reaction; and (6) symbols of elements and compounds involved in exothermic reactions.

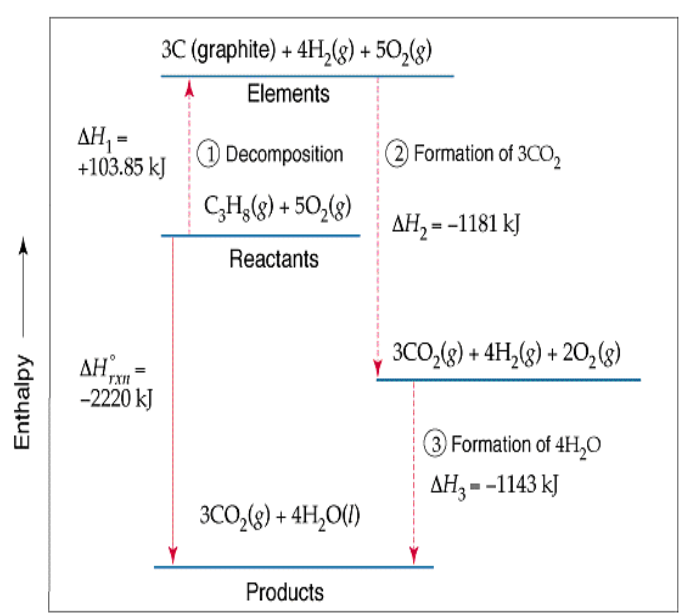

Figure 2. Exothermic reaction graph

The student's ability to identify symbolic representations in graph is given a score of 2 for each identified symbolic representation.For the ability to identify graphic symbolic representations, the percentage of the maximum score (6 correct statements) to the minimum score (2 correct statements), is shown as follows: $8.3 \%$; $29.4 \% ; 55.3 \% ; 3.5 \%$; and $3.5 \%$. The results of the analysis show that on average students only find four of the six representations, namely numbers 3 to 6 .

The average value of students' ability to identify the symbolic representation of the two parts of the questions given is shown in Table 1 below.

Table 1. The average value of students

\begin{tabular}{|c|c|c|c|}
\hline Interval & $\boldsymbol{x i}$ & $\boldsymbol{f i}$ & $\boldsymbol{x i} \boldsymbol{f i}$ \\
\hline $33-41$ & 37 & 6 & 222 \\
\hline $42-50$ & 46 & 11 & 506 \\
\hline $51-59$ & 55 & 9 & 495 \\
\hline $60-68$ & 64 & 15 & 960 \\
\hline $69-77$ & 73 & 31 & 2263 \\
\hline $78-86$ & 82 & 10 & 820 \\
\hline $87-95$ & 91 & 3 & 273 \\
\hline & & 85 & mean $=\mathbf{6 5 , 1 6}$ \\
\hline
\end{tabular}

From the average value, it appears that students' ability to identify symbolic representations, especially in the form of mathematical modeling (exothermic reaction graph), is still not optimal. This is not in line with the opinion of Widodo, et al (2020), that mathematical modeling skills as one of the epistemic knowledge must be formed in prospective science teacher students. Through mathematical modeling students can make mathematical relationships between symptoms with one another. 


\section{CONCLUSION}

From this study, it was found that out of ten symbolic representation statements, only three achieved the highest percentage of correct answers, so students had to be frequently faced with various symbolic representations in chemistry in order to become familiar. Identification of symbolic representations from graphs, on average students are only able to identify four of the six representations. It can be concluded that students' ability to identify symbolic representations in chemistry still needs to be improved, because the average score is still low.

\section{REFERENCES}

Chandrasegaran, A. L., Treagust, D. F., \& Mocerino, M. (2007). Enhancing students' use of multiple levels of representation to describe and explain chemical reactions. School Science Review, 88(325), 115.

Demirel, Y. Gerbaud, V. (2019).Transport and Rate Processes in Nonequilibrium Thermodynamics (Fourth Edition). https://www.sciencedirect.com/topics/engineer ing/microscopic-domain

Ebbing, DD. and Gammon, SD. (2009). General Chemistry. Ninth Edition. New York: Houghton Mifflin Company.
Garza, AMED. Grajales, WPU. (2011). A Guidebook for Assessing Learning. Mexico: Impreso.

https://www.researchgate.net/publication/2249 $\underline{62133 .}$.

Johnstone, A. H. (1991). Why is science difficult to learn? Things are seldom what they seem. Journal of computer assisted learning, 7(2), 75-83.

Sujak, KB. Daniel, EGS (2017).Understanding of Macroscopic, Microscopic and Symbolic Representations Among Form Four Students in Solving Stoichiometric Problems. Malaysian Online Journal of Educational Sciences 2017 (Volume5 - Issue 3 )

Sunyono, Leny Yuanita, Muslimin Ibrahim, (2015), Mental Models of Students on Stoichiometry Concept in Learning by Method Based on Multiple Representation. The Online Journal of New Horizons in Education - April 2015, 5(2),30-45.

Widodo, W. Sari, D.A.P. Suryanto, T. Martini, Inzanah. (2020). Pengembangan keterampilan pemodelan matematis untuk calon guru IPA. Jurnal Inovasi Pendidikan IPA, 6 (2), 2020, 146-155.

William R. Robinson. (2015). Chemistry. OpenStax Colledge. Houston: Rice University. 